\title{
Improved ROS defense in the swimbladder of a facultative air-breathing erythrinid fish, jeju, compared to a non-air-breathing close relative, traira
}

\author{
Bernd Pelster $^{1,2} \cdot$ Marina Giacomin $^{3} \cdot$ Chris M. Wood $^{3} \cdot$ Adalberto L. Val $^{4}$
}

Received: 22 December 2015 / Revised: 14 March 2016 / Accepted: 19 March 2016 / Published online: 5 April 2016

(C) The Author(s) 2016. This article is published with open access at Springerlink.com

\begin{abstract}
The jeju Hoplerythrinus unitaeniatus and the traira Hoplias malabaricus are two closely related erythrinid fish, both possessing a two-chambered physostomous swimbladder. In the jeju the anterior section of the posterior bladder is highly vascularized and the swimbladder is used for aerial respiration; the traira, in turn, is a water-breather that uses the swimbladder as a buoyancy organ and not for aerial oxygen uptake. Observation of the breathing behavior under different levels of water oxygenation revealed that the traira started aquatic surface respiration only under severe hypoxic conditions and did not breathe air. In the jeju air-breathing behavior was observed under normoxic conditions, and the frequency of air-breathing was significantly increased under hypoxic conditions. Unexpectedly, even under hyperoxic conditions $\left(30 \mathrm{mg} \mathrm{O}_{2} \mathrm{~L}^{-1}\right)$ the jeju continued to take air breaths, and compared with normoxic conditions the frequency was not reduced. Because the frequently air-exposed swimbladder tissue faces higher oxygen partial pressures than normally experienced by other fish tissues, it was hypothesized that in the facultative airbreathing jeju, swimbladder tissue would have a higher antioxidative capacity than the swimbladder tissue of the
\end{abstract}

Communicated by G. Heldmaier.

Bernd Pelster

bernd.pelster@uibk.ac.at

1 Institute of Zoology, University of Innsbruck, Technikerstr. 25, 6020 Innsbruck, Austria

2 Center for Molecular Biosciences, University Innsbruck, Innsbruck, Austria

3 Department of Zoology, University of British Columbia, Vancouver, BC V6T 1Z4, Canada

4 Instituto Nacional de Pesquisas da Amazônia, Manaus, Brazil water breathing traira. Measurement of total glutathione (GSSG/GSH) concentration in anterior and posterior swimbladder tissue revealed a higher concentration of this antioxidant in swimbladder tissue as compared to muscle tissue in the jeju. Furthermore, the GSSG/GSH concentration in jeju tissues was significantly higher than in traira tissues. Similarly, activities of enzymes involved in the breakdown of reactive oxygen species were significantly higher in the jeju swimbladder as compared to the traira swimbladder. The results show that the jeju, using the swimbladder as an additional breathing organ, has an enhanced antioxidative capacity in the swimbladder as compared to the traira, using the swimbladder only as a buoyancy organ.

Keywords Swimbladder · Erythrinid fish · Reactive oxygen species $\cdot$ ROS defense $\cdot$ Oxygen partial pressure

\section{Introduction}

The oxygen concentration in aquatic systems, in particular in the Amazon Basin, is known to vary greatly (Val and Almeida-Val 1995; Muusze et al. 1998; Diaz and Breitburg 2009; Welker et al. 2013). Oxygen is essential for aerobic metabolism and ATP production, and reduced oxygen availability frequently results in metabolic depression (St-Pierre et al. 2000; Guppy 2004; van Ginneken and van den Thillart 2009; Ali et al. 2012). To supplement oxygen supply during aquatic hypoxia, many fish of the Amazon Basin rely on aquatic surface respiration or even use specific tissues or organs for aerial gas exchange (Val and Almeida-Val 1995). For example, members of the Loricariidae and the Callichthyidae families frequently use their vascularized stomach or intestine for aerial gas exchange, the tambaqui picks up oxygen from the water surface with a largely extended inferior 
lip under hypoxic conditions, and some species of the Erythrinidae family of fish use the swimbladder to extract oxygen from the air. Pharyngeal, branchial and mouth diverticula are found among the Electrophoridae and the Synbranchidae, while the South-American lungfish Lepidosiren paradoxa takes most of the oxygen required for aerobic metabolism using its well-developed lung (Bemis et al. 1987; Val and Almeida-Val 1995; Glass and Rantin 2009).

While oxygen is essential for aerobic metabolism, it may also result in the production of reactive oxygen species (ROS). ROS are mainly generated by electrons escaping from the mitochondrial electron transport chain and by NADPH-oxidase. To a minor extent the endoplasmic reticulum with cytochrome $\mathrm{P} 450$ and different cellular oxidases may also contribute to ROS production (Chandel and Budinger 2007; Lushchak 2011). The accumulation of ROS causes oxidative stress (Lushchak 2014; Sies 2015) and results in lipid peroxidation, protein carbonylation, and/or DNA modifications, i.e., formation of oxidized bases, in particular 8-oxoguanine (Lushchak 2011). In consequence, the inordinate accumulation of ROS causes serious tissue damage and is harmful for the whole organism.

Hyperoxia stimulates the generation of ROS, and hyperoxic conditions have been shown to result in transient oxidative stress in goldfish tissues (Lushchak et al. 2005a; Lushchak and Bagnyukova 2006; Lushchak 2011). Normoxic recovery following transient exposure to hypoxic conditions also sharply increases the ROS level, resulting in oxidative stress (Halliwell and Gutteridge 1989; Li and Jackson 2002; Hermes-Lima 2004; Gorr et al. 2010). Meanwhile it has been shown repeatedly that reduced oxygen availability (hypoxia) may also cause oxidative stress (Welker et al. 2013), which in fish occurs, for example, in goldfish Carassius auratus (Lushchak et al. 2001), common carp Cyprinus carpio (Lushchak et al. 2005b), rotan Perccottus glenii (Lushchak and Bagnyukova 2007), and the Indian catfish Clarias batrachus (Tripathi et al. 2013).

These considerations show that ROS are frequently expected in nature with changing oxygen availability and in tissues exposed to high $\mathrm{PO}_{2}$, and organisms have developed sophisticated defense systems to break down and detoxify reactive oxygen molecules (Hermes-Lima 2004; Lushchak 2011; Summarwar and Verma 2012; Welker et al. 2013; Lushchak 2014). These can include the accumulation of antioxidants like glutathione, ascorbic acid (vitamin C), retinol (vitamin A) or $\alpha$-tocopherol (vitamin E). In addition, several enzymes are able to remove ROS, and these include catalase, superoxide dismutase (SOD), glutathione reductase (GR) and glutathione peroxidase (GPx). Glucose-6-phosphate dehydrogenase may also be mentioned in this context. This enzyme contributes to the pentose phosphate shunt and generates NADPH, which is required for the regeneration of GSH in the GR reaction.
The concentration of antioxidants and the activity of enzymatic antioxidants have been analyzed in many tissues and several species of fish under different environmental stress conditions [see (Lushchak and Bagnyukova 2006; Lushchak 2011; Welker et al. 2013)]. These studies clearly showed that the defense system against ROS is not static but highly responsive to changing environmental conditions. A significant increase in ROS degrading enzyme activities and in the concentration of antioxidants is, for example, frequently observed following periods of hypoxia. HermesLima et al. (1998) proposed that hypoxia prepares the organism for oxidative stress encountered during recovery from hypoxia, and the concept of a preparation for oxidative stress is widely accepted (Welker et al. 2013).

Particularly high activities of enzymes involved in ROS degradation are typically found in tissues prone to be exposed to ROS like the liver (Lushchak et al. 2005a; Bagnyukova et al. 2006), or the lung in mammals, which faces the highest oxygen concentrations in mammalian tissues (Erzurum et al. 1993; Ho et al. 2001; Hackett et al. 2003). In marine fish high activities are also found in swimbladder tissue (Morris and Albright 1981, 1984), because the swimbladder of physoclist fish typically contains high concentrations of oxygen and with increasing hyperbaric pressure at depth becomes extremely hyperoxic (Pelster 1997, 2011, 2015). $\mathrm{PO}_{2}$ in the swimbladder of fish breathing air cannot be as high as in fish swimming at depth, but they certainly are higher than in most other tissues, except for gills and skin, because arterial oxygen partial pressure of water breathing fish typically is much lower than aerial $\mathrm{PO}_{2}$ (Gilmour and Perry 1994; Kristensen et al. 2010). $\mathrm{PO}_{2}$ in the physostomous swimbladder of fish using the swimbladder for breathing air should also be higher than in fish using the swimbladder only as a buoyancy structure. In fish breathing air, the swimbladder gas is renewed frequently with fresh air, but in fish using the bladder as a buoyancy structure, fresh air is engulfed only occasionally. In the intervening period, however, gases are resorbed according to their physical solubility, and this means that nitrogen is accumulated in the swimbladder, replacing oxygen (Piiper et al. 1962; Piiper 1965). We therefore hypothesized that the swimbladder tissue of a freshwater fish using the swimbladder for aerial respiration would be equipped with an enhanced ROS defense system compared with a swimbladder of a closely related fish where the swimbladder is used only as a buoyancy organ, and with other fish tissues.

To test this hypothesis we examined two closely related erythrinid fish, the jeju, Hoplerythrinus unitaeniatus, and the traira, Hoplias malabaricus. Both fish have a swimbladder consisting of an anterior and a posterior chamber, connected to the esophagus via a ductus pneumaticus. In the facultative air-breathing jeju the anterior section of the posterior swimbladder is highly vascularized, and it is used for 
aerial gas exchange. Previous studies have indeed shown that swimbladder $\mathrm{PO}_{2}$ in the jeju may even reach $20 \mathrm{kPa}$ in the anterior bladder (Kramer 1978), and Farrell and Randall (1978) estimated a value of about $18 \mathrm{kPa}$. In traira, neither the anterior nor the posterior part of the bladder shows a dense vascularization and the bladder is likely used as a buoyancy organ, but not for aerial gas exchange (Val and Almeida-Val 1995).

\section{Materials and methods}

All experiments were performed in December 2013 and December 2014 on board a research vessel (the Anna Clara, from Manaus) during two expeditions to the Anavilhanas Archipelago of the Rio Negro, approximately $110 \mathrm{~km}$ upstream from Manaus. All procedures were in compliance with Brazilian national and Instituto Nacional de Pesquisas da Amazônia (INPA) animal care regulations.

Erythrinid fish used for this study, the jeju and the traira, were caught by INPA fishermen. Body mass of jeju used for these experiments was $160 \pm 23 \mathrm{~g}$, fork length $23.1 \pm 1.2 \mathrm{~cm}(N=15)$ and of traira $147 \pm 18 \mathrm{~g}$, fork length $25.3 \pm 1.2 \mathrm{~cm}(N=14)$. Both species were held on board in large tanks served with flowing "black water" pumped directly from the Rio Negro (temperature $\left.=30-35{ }^{\circ} \mathrm{C}, \mathrm{pH}=4.0-4.5\right)$. These values are normal for this river, which supports an abundant fish fauna adapted to these extreme conditions (Val and Almeida-Val 1995). In the tanks the fish had free access to air and could therefore breathe air voluntarily. Fish were not fed during the 12-day expeditions and were allowed to recover at least overnight after capture before experimentation.

\section{Behavioral studies}

For behavioral studies individual fish were transferred into individual cylindrical 25-30 L glass containers, filled with Rio Negro water (temperature $=30-35^{\circ} \mathrm{C}, \mathrm{pH}=4.0-4.5$ ). The differences in river water temperature were encountered between different days during the field trip depending on the weather conditions. However, within an individual experiment temperature did not vary by more than $2{ }^{\circ} \mathrm{C}$. The glass containers were separated from other tanks so that the fish could not see each other, and the fish were allowed to settle for at least $1 \mathrm{~h}$. After this time fish never showed any signs of stress or increased swimming activity. The water surface was uncovered and the fish could take air breaths completely unhindered. The water was aerated using air stones (normoxia $=7-8 \mathrm{mg} \mathrm{O}_{2} \mathrm{~L}^{-1}$, corresponding to a $\mathrm{PO}_{2}$ of $20 \mathrm{kPa}$ ), or gassed with oxygen to achieve hyperoxic conditions $\left(30 \mathrm{mg} \mathrm{O} \mathrm{O}^{-1}\right.$, corresponding to a $\mathrm{PO}_{2}$ of $80 \mathrm{kPa}$ ). Hypoxic conditions were achieved by gassing the water with nitrogen until an oxygen content of about $0.5 \mathrm{mg} \mathrm{O}_{2} \mathrm{~L}^{-1}$ (corresponding to a $\mathrm{PO}_{2}$ of $1.3 \mathrm{kPa}$ ) was reached. Treatments were assigned randomly to 10 jeju and 11 traira. Water oxygen concentration and partial pressure were recorded with a portable oxygen electrode and meter (WTW Oxi325 Oximeter, Weilheim, Germany). The air-breathing behavior of each fish was observed for up to $4 \mathrm{~h}$ between $10 \mathrm{am}$ and $6 \mathrm{pm}$, and sequences were recorded using a Nikon D7100 camera. The number of air-breaths taken per unit of time was counted for the jeju. Air-breaths could easily be identified because immediately after leaving the surface air bubbles left the opercular cavity via the operculum. For traira, the frequency of aquatic surface respiration (ASR) was recorded. In addition, the \% of time spent at the surface was calculated for both species by measuring the time required for each air-breathing event (jeju) or for aquatic surface respiration ASR (traira) (Kramer and Mehegan 1981) and dividing it by total observation time.

\section{Tissue preparation}

Fish maintained under normoxic conditions were killed with an overdose of tricaine methanesulfonate (MS222; $0.3 \mathrm{~g} \mathrm{~L}^{-1}$ ). Fish were opened ventrally and the swimbladder was carefully dissected. Connective tissue was removed and the remaining tissue was carefully rinsed and cleaned in Cortland saline (Wolf 1963) and blotted dry. The anterior swimbladder tissue of jeju and traira and also the posterior part of traira swimbladder was dissected into small portions and immediately frozen in liquid nitrogen. For jeju, only the vascularized (first) part of the posterior swimbladder tissue was used for tissue preparation. Pieces of white muscle tissue were taken close to the lateral line near the anus and immediately frozen in liquid nitrogen. Tissues were then stored in a biofreezer at $-80^{\circ} \mathrm{C}$ until further analysis.

\section{Biochemical analysis}

For determination of total glutathione (GSSG/GSH) content of the frozen tissue samples, tissue extracts were prepared using $5 \%$ metaphosphoric acid (MPA). The frozen tissues were ground to a fine powder and dissolved $1: 5 \mathrm{w} / \mathrm{v}$ in $5 \%$ MPA. Under ice cooling the solution was homogenized using a motorized homogenizer. Extracts were centrifuged at $13,000 \mathrm{rpm}$ for $5 \mathrm{~min}$ at $4{ }^{\circ} \mathrm{C}$ and the supernatant was diluted using assay buffer for GSSG/GSH determination. GSSG/GSH concentration was determined using the OxiSelect Total Glutathione (GSSG/GSH) Assay Kit (STA-312) Cell Biolabs, Inc, San Diego, USA, following the manufacturer's instructions.

For measurement of enzyme activities the frozen tissue samples were homogenized on ice in 1:5 w/v of ice-cold homogenization buffer $(10 \mathrm{mM}$ TRIS/HCl, $0.1 \mathrm{mM}$ disodium EDTA, $150 \mathrm{mM} \mathrm{NaCl}, \mathrm{pH} 7.5$ at $25^{\circ} \mathrm{C}$ ). Under ice 
cooling, the solution was homogenized using a motorized homogenizer. Homogenates were centrifuged at 13,000 rpm for $15 \mathrm{~min}$ at $4{ }^{\circ} \mathrm{C}$ and appropriate dilutions of the supernatant were used for the enzyme and protein assays.

Enzyme activities were measured using a SpectraMax 384Plus microplate spectrophotometer (Molecular Devices, Sunnyvale, CA, USA) with temperature control at $25 \pm 0.1^{\circ} \mathrm{C}$. Glutathione reductase (GR; EC 1.6.4.2.) and glutathione peroxidase (GPx; EC 1.11.1.9.) activity was measured using the Glutathione Reductase Assay Kit (No 703202; Cayman Chemical Company, Ann Harbor, USA), and the Glutathione Peroxidase Assay Kit (No 703102; Cayman Chemical Company, Ann Harbor, USA).

Catalase (Cat; EC 1.11.1.6.) activity was assayed using the Amplex Red Catalase Assay Kit (A22180; Molecular Probes, Eugene, USA). Superoxide dismutase (SOD; EC 1.15.1.1.) activity was measured following a procedure described by (McCord and Fridovich 1969). Briefly, reactive oxygen species generated from xanthine in the xanthine oxidase reaction cause a reduction of cytochrome $c$, which is inhibited by the presence of SOD. One unit of SOD activity is defined as the amount of enzyme (per milligram of protein) that inhibits the reduction of cytochrome $c$ observed in the blank without SOD by $50 \%$.

Protein concentration in the homogenate was measured with Coomassie Brilliant Blue G-250 (Bradford 1976) using bovine serum albumin as a standard.

\section{Statistics}

Data have been expressed as mean \pm 1 SEM with $N$ giving the number of animals analyzed in each species. GSSG/ GSH concentrations are given as $\mu \mathrm{mol} \mathrm{g}^{-1}$ wwt (wet weight),

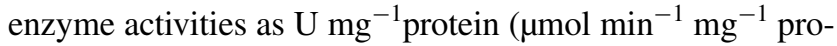
tein). For statistical analysis two-way repeated measures Anova, followed by the Holm-Sidak multiple comparison procedures, was used. Fish species (jeju, traira) and tissue (muscle, anterior bladder, posterior bladder) were used as parameters (factors) 1 and 2, and enzyme activity or GSH/ GSSG concentration as variables (data). Air-breathing frequency and \% time spent at the surface were analyzed using one-way Anova followed by Tukey's post hoc test. In rare cases the normality test or equal variance test failed using the original data. In this case the data were log transformed prior to statistical analysis. The statistical analysis was performed using SigmaPlot 12.0. Statistical differences between values were accepted for $p<0.05$.

\section{Results}

Behavioral observation confirmed that the jeju is a facultative air-breather, repeatedly visiting the surface to take
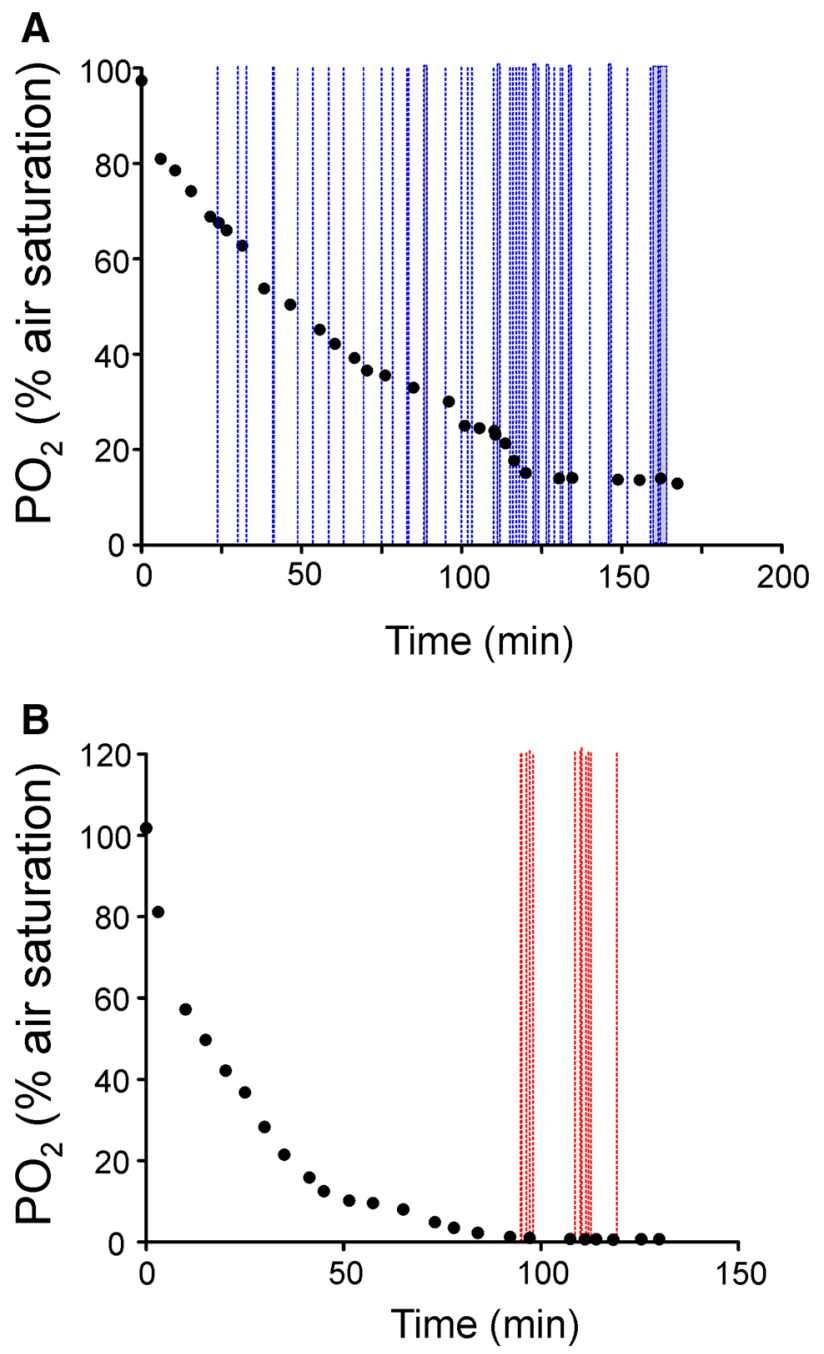

Fig. 1 A Air-breathing activity in the jeju in an individual experiment with progressive hypoxia. Each dashed blue line indicates a single air-breath. Air-breathing frequency was significantly elevated under hypoxic conditions. B Aquatic surface respiration activity $(A S R)$ in an individual traira. In traira air-breathing was never observed. Under severe hypoxia traira started ASR. Each dashed red line indicates a single ASR event. Black dots indicate individual oxygen measurements documenting the declining $\mathrm{PO}_{2}$. Observations ended after the final $\mathrm{PO}_{2}$ measurement (color figure online)

an air-breath under normoxic conditions. With decreasing $\mathrm{PO}_{2}$ in the water the frequency of air-breathing increased, as shown for an individual jeju in Fig. 1A. Surprisingly, in the jeju this air-breathing behavior was also routinely observed under hyperoxic conditions (Fig. 2). Air-breathing was never observed in traira, and this species did not visit the water surface for aquatic surface respiration (ASR) under either normoxia or hyperoxia. However, ASR was observed when water $\mathrm{PO}_{2}$ was below $5 \%$ of air saturation, i.e., close to zero, as shown for an individual fish in Fig. 1B. The fish swam to the water surface opening the jaws just beneath the surface. However, in the traira 
Fig. 2 Quantitative analysis of the air-breathing and ASR activity of jeju $(N=10)$ and traira $(N=9)$. A Number of air-breaths per hour in jeju under normoxic, hypoxic and hyperoxic conditions. B Number of ASR events per hour in traira under normoxia, hypoxia and hyperoxia. C, D $\%$ of time spent at the surface for air-breathing or ASR in jeju (C) and traira (D), respectively. Small letters denote significant differences between normoxia, hypoxia and hyperoxia $(p<0.05)$. Bars without letters are not different from each other
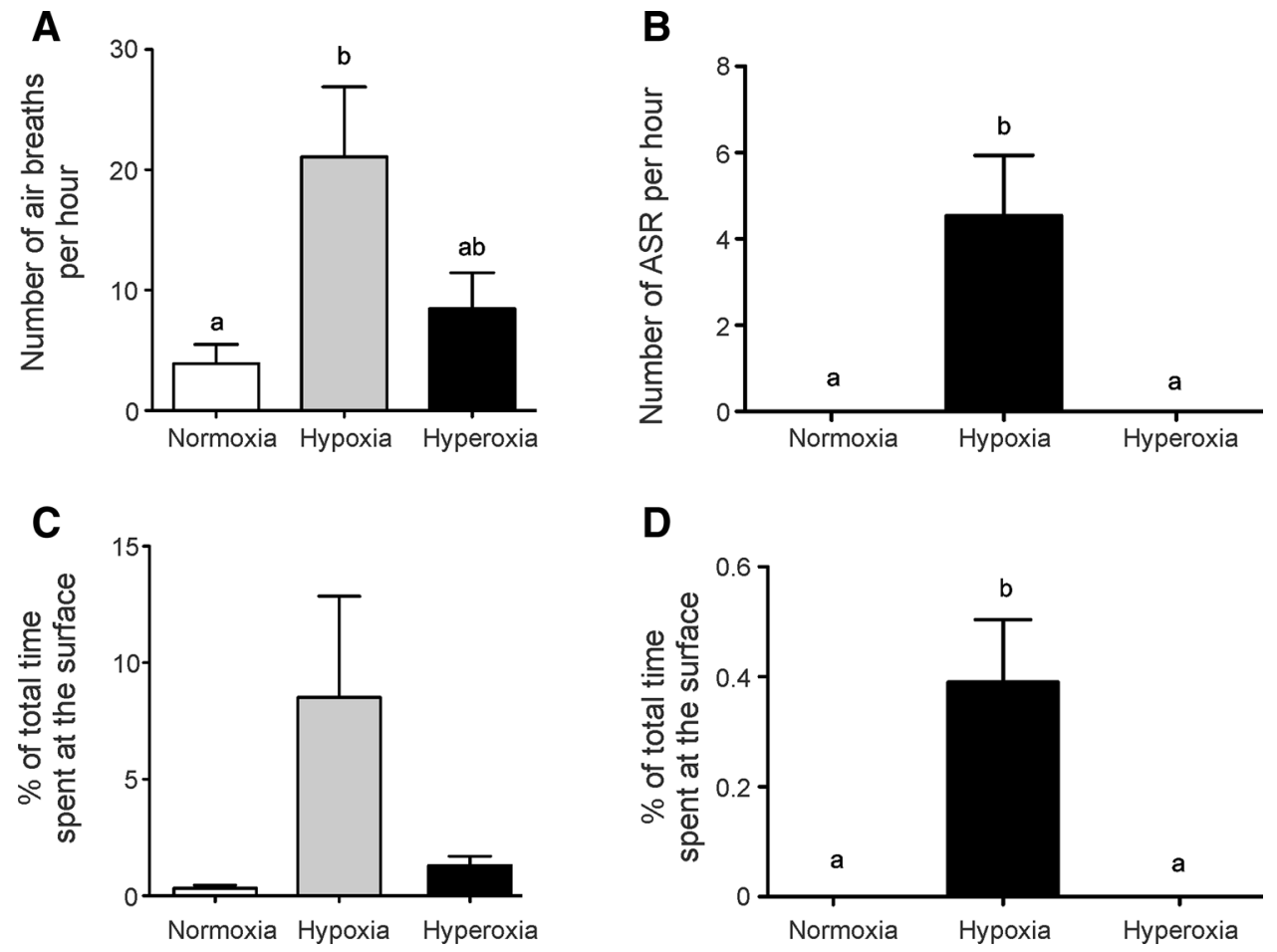

D

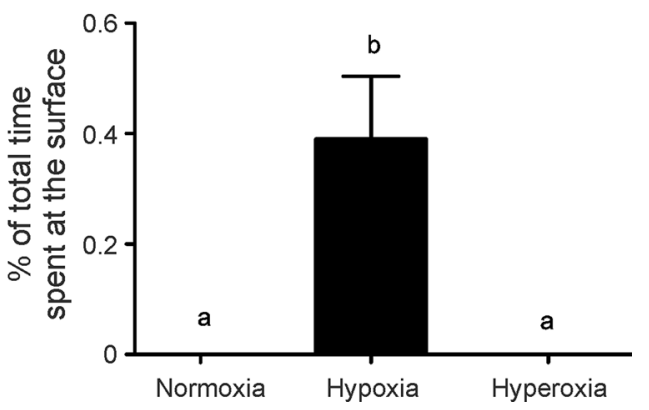

the release of an air bubble from the gill cavity was never observed.

Quantitative analysis of air-breathing behavior (jeju) and of ASR (traira) is shown in Fig. 2. Under normoxic conditions the jeju spent close to $1 \%$ of the observed time at the surface breathing air, and under hyperoxic this air-breathing activity was not reduced. Under hypoxic conditions the jeju visited the surface 21.7 times per hour and spent $8.6 \%$ of the time for surface respiration, which was significantly higher than under normoxic or hyperoxic conditions (Fig. 2A, C). The traira in turn started aquatic surface respiration (ASR) under hypoxic conditions and visited the surface 4.4 times per hour, spending about $0.4 \%$ of the time at the surface (Fig. 2B, D). Accordingly, hypoxia significantly stimulated air-breathing behavior (jeju) and ASR (traira), respectively, in the two species.

To assess the antioxidative capacity of swimbladder tissue we measured total glutathione concentration (GSSG/ $\mathrm{GSH}$ ) in the anterior and in the posterior swimbladder tissue, including also muscle tissue for comparison as a tissue that is not directly exposed to high oxygen partial pressures (Fig. 3). A comparison of the two erythrinid species revealed a significantly higher GSSG/GSH concentration in all examined tissues of the jeju, and two-way RM Anova revealed differences between the two species $(p<0.001$, $\left.F_{1,9}=203.328\right)$. In the jeju swimbladder in both sections the concentration of total GSSG/GSH was significantly higher as compared to muscle tissue $(p<0.001$ for anterior versus muscle and for posterior versus muscle; $p=0.32$ for

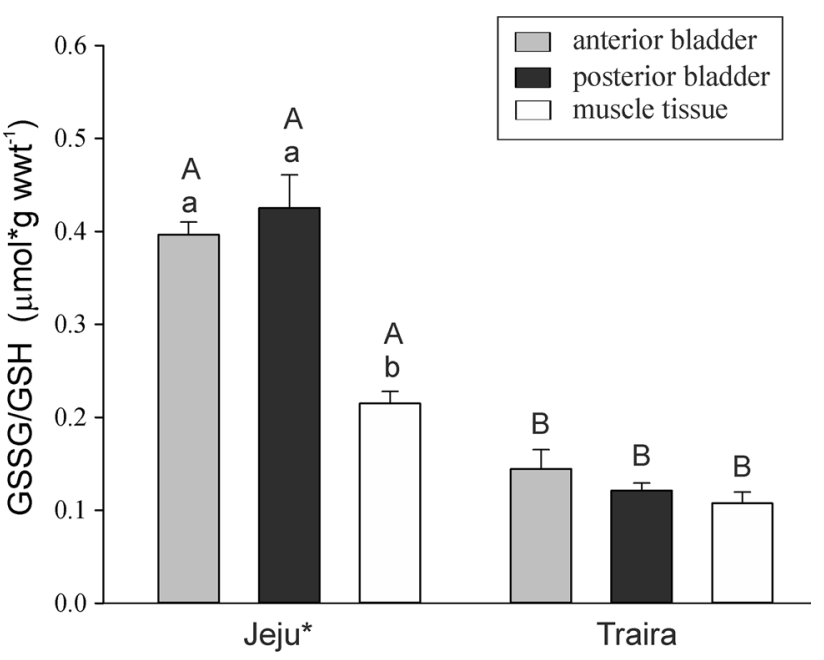

Fig. 3 Total GSSG/GSH concentration in anterior and posterior swimbladder tissue and in muscle tissue of jeju and of traira. Small letters denote significant differences between tissues within a species, capital letters denote significant differences between the two species $(N=6 ; p<0.05)$

anterior versus posterior) (Fig. 3). In traira no significant difference was detected between swimbladder tissue and muscle tissue ( $p>0.1$ for all comparisons).

At the species level catalase activity was higher in jeju $\left(p<0.05 ; F_{1,14}=6.007\right)$, and in posterior swimbladder tissue of jeju catalase activity was higher than in posterior swimbladder tissue of traira $(p<0.01)$ (Fig. 4). Comparison 
of swimbladder and muscle tissue of jeju revealed higher catalase activity in posterior swimbladder tissue as compared to muscle tissue $(p<0.01)$. No difference in catalase activity was detected among the three traira tissues analyzed.

SOD activity was very similar in the tissues of jeju and traira, and there was no significant difference between the two species (Fig. 5). Similarly, no significant difference was detected among the different tissues of either jeju or traira.

Significant differences were identified between the two species with respect to GR activity $(p<0.001$; $\left.F_{1,14}=72.748\right)$. Comparing the three individual tissues GR activity was higher in jeju tissues $(p<0.001$ for anterior and posterior swimbladder tissue; $p<0.05$ for muscle tissue) (Fig. 6A). The highest activity was recorded in posterior swimbladder tissue of jeju, followed by the anterior swimbladder. Within jeju all three tissues were different in GR activity, muscle tissue showing the lowest activity. Within traira no difference in the GR activity was detected between muscle and swimbladder tissue.

At the species level GPx activity was not different between jeju and traira, but in the anterior part of jeju swimbladder GPx activity was higher than in anterior swimbladder tissue of traira $(p<0.01)$ (Fig. 6B). The highest GPx activity was found in anterior swimbladder tissue of the jeju with $35.3 \pm 7.1 \mathrm{mU} \mathrm{mg}^{-1}$ protein (Fig. 6B), and the activity was higher than in posterior swimbladder tissue or muscle tissue of the jeju. In traira again no difference was detected in GPx activity when comparing swimbladder and muscle tissue (Fig. 6B).

\section{Discussion}

In behavioral studies on the jeju we observed air-breathing behavior under normoxic conditions, while in previous studies air-breathing was not observed at $\mathrm{PO}_{2}$ values above $42.5 \%$ air saturation $\left(\mathrm{PO}_{2}=8.5 \mathrm{kPa}\right)$ (Perry et al. 2004; Oliveira et al. 2004). In the latter studies air-breathing was only observed at lower $\mathrm{PO}_{2}$ values, reaching a maximum of 20 or 36 breathing events per hour at a $\mathrm{PO}_{2}$ of $2.3 \mathrm{kPa}$. It is quite possible that in our study jeju resorted to air-breathing at normoxia due to higher temperatures, which increase metabolic activity. Our experiments were performed in the field using water from the river at river temperature, while the other two studies were performed in the lab at $25^{\circ} \mathrm{C}$. In the present study 21.7 breaths per hour were observed at the lowest $\mathrm{PO}_{2}$. A much lower frequency of only 5.6 breaths per hour was observed by Juca-Chagas (Juca-Chagas 2004) at a $\mathrm{PO}_{2}$ of below $3.3 \%$ air saturation $\left(\mathrm{PO}_{2}=0.67 \mathrm{kPa}\right)$. These experiments were performed at a temperature of $25{ }^{\circ} \mathrm{C}$, which may have contributed

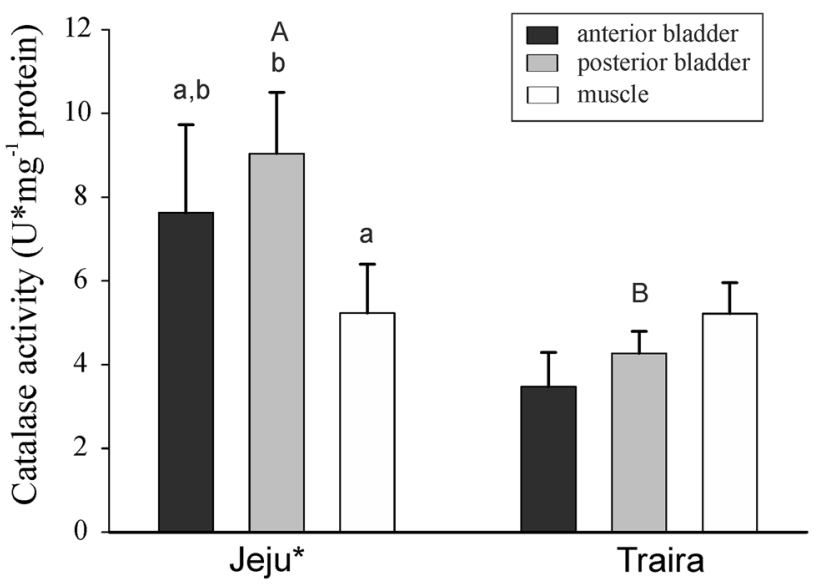

Fig. 4 Catalase activity in $\mathrm{U} \mathrm{mg}^{-1}$ protein in anterior and posterior swimbladder tissue and in muscle tissue of jeju and of traira. Capital letters denote significant differences between the two species, bars without letters are not significantly different; asterisk indicates significant overall difference between the two species (jeju, $N=11$; traira, $N=9 ; p<0.05)$

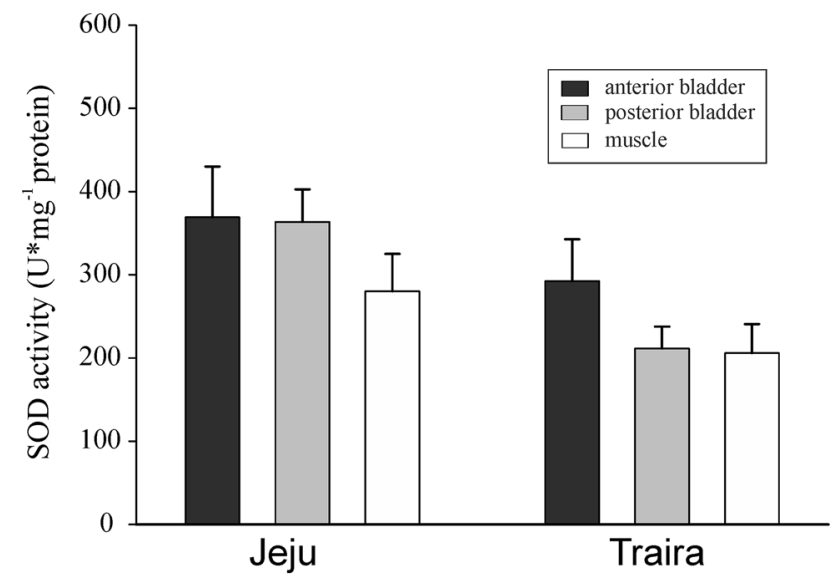

Fig. 5 SOD activity in $\mathrm{U} \mathrm{mg}^{-1}$ protein in anterior and posterior swimbladder tissue and in muscle tissue of jeju and of traira. Capital letters denote significant differences between the two species, bars without letters are not significantly different (jeju, $N=11$; traira, $N=10 ; p<0.05)$

to these lower values, but Perry et al. (2004) counted 36 breathing events per hour at a $\mathrm{PO}_{2}$ of $13 \%$ air saturation $\left(\mathrm{PO}_{2}=2.6 \mathrm{kPa}\right)$ at the same temperature. Accordingly, temperature does not appear the only explanation for these differences. A stimulation of air-breathing behavior by severe hypoxia has also been reported in previous studies on the jeju (Kramer et al. 1978; Stevens and Holeton 1978). Quite surprising and unexpected was the observation that hyperoxia did not reduce air-breathing activity in the jeju. Following the hypothesis that aquatic hypoxia stimulates aerial respiration in fish (Daniels et al. 2004), it could be 

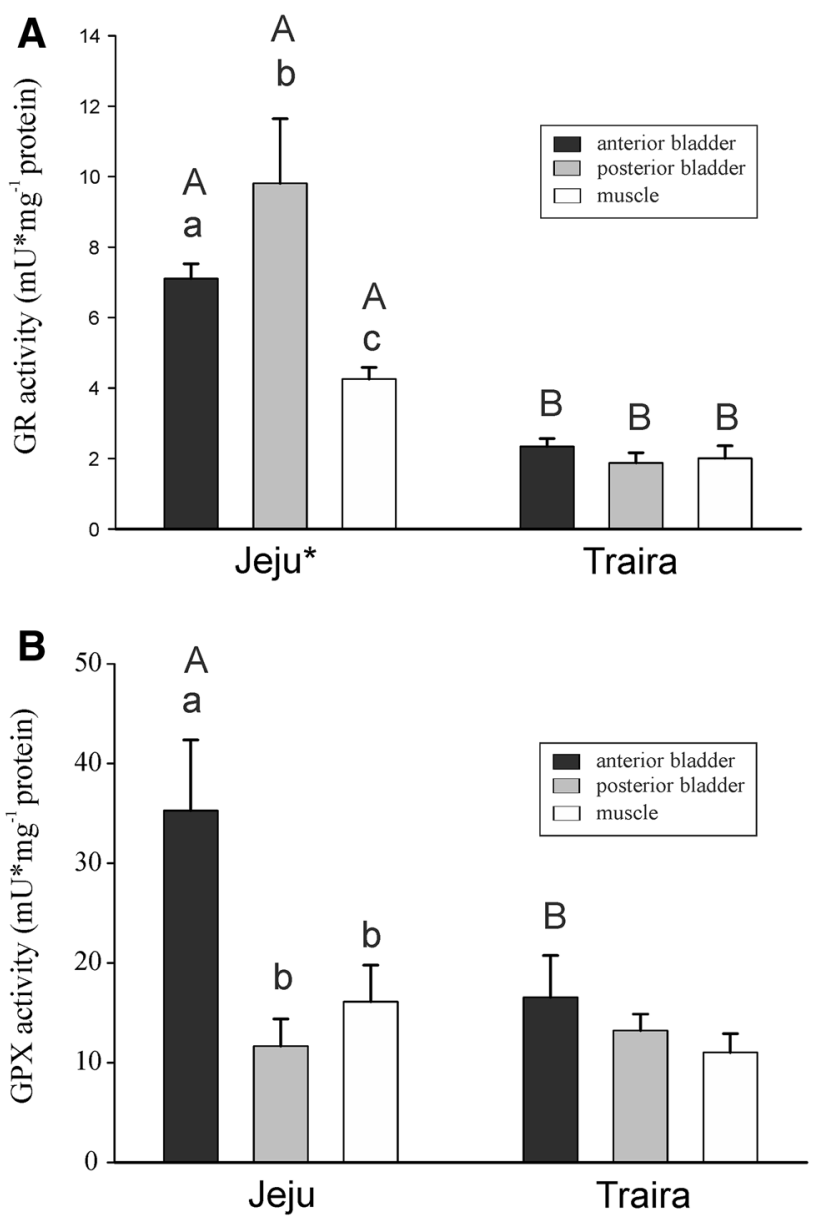

Fig. 6 Glutathione reductase (A) and glutathione peroxidase (B) activity in $\mathrm{mU} \mathrm{mg}^{-1}$ protein in anterior and posterior swimbladder tissue and in muscle tissue of jeju and of traira. Small letters denote significant differences between tissues within a species, capital letters denote significant differences between the two species, bars without letters are not significantly different, asterisk indicates significant overall difference between the two species $(N=8 ; p<0.05)$

expected that surplus oxygen in the water will reduce airbreathing activity. This observation supported the conclusion that temperature alone was not the clue for initiation of normoxic air-breathing behavior in the jeju in our experiments, because normoxic and hyperoxic conditions were encountered at the same temperature in individual fish. The elevated oxygen supply in the water under hyperoxia therefore should have reduced the necessity to supplement aquatic oxygen uptake by breathing air. One possible explanation for the air-breathing activity at hyperoxic $\mathrm{PO}_{2}$ in the water could be that the high $\mathrm{PO}_{2}$ will increase ROS production, and in this situation breathing air with normoxic $\mathrm{PO}_{2}$, rather than water with hyperoxic $\mathrm{PO}_{2}$, may be advantageous for the tissues. In our experiments oxygen partial pressure of the water was changed, while the air space was open to the environment and not experimentally modified.
Accordingly, the air taken up into the swimbladder should have been close to normoxic under all experimental conditions. Nevertheless, the jeju showed a clear behavioral response to changes in water $\mathrm{PO}_{2}$. Lopes et al. (2010) have shown that stimulation of branchial chemoreceptors induced air breathing behavior in the jeju and assumed that internal hypoxaemia is the primary drive to stimulate air-breathing.

The traira is not an air-breathing fish (Rantin et al. 1992), and Glass and Rantin (Glass and Rantin 2009) reported that it completely depends on gill ventilation, even under hypoxic conditions. However, our observations clearly revealed that the traira started aquatic surface respiration (ASR) when water $\mathrm{PO}_{2}$ dropped to very low values. This behavior, previously described for a number of tropical freshwater fish (Kramer and Mehegan 1981; Kramer and McClure 1982), can be seen as a step prior to air breathing in evolutionary terms. The fish uses the water just beneath the water surface for ventilation. Because of diffusion from air into the water, the surface layer with close contact to the air should have the highest $\mathrm{PO}_{2}$.

In freshwater fish using the swimbladder as an accessory air-breathing organ, the oxygen partial pressures will not be as high as in the swimbladder of marine fish swimming at depth using the bladder as buoyancy organ [see (Steen 1963; Kobayashi et al. 1990; Pelster 1997, 2009, 2011)], but they are expected to be higher than oxygen partial pressures of most tissues of purely water breathing fish. In normoxic Atlantic salmon Salmo salar arterial $\mathrm{PO}_{2}$ is lower than water $\mathrm{PO}_{2}$ (Kristensen et al. 2010), and in dorsal arterial blood of traira and jeju $\mathrm{PO}_{2}$ values of 10 and $4 \mathrm{kPa}$ have been reported (Stevens and Holeton 1978; Randall et al. 1978; Perry et al. 2004), respectively. This is much lower than the average $\mathrm{PO}_{2}$ of $13.3 \mathrm{kPa}$ reported for anterior swimbladder of jeju, and even values of up to 18 and $20 \mathrm{kPa}$ have been measured in jeju swimbladder (Farrell and Randall 1978; Kramer 1978). Due to the rare uptake of air into the swimbladder of traira, which is used for buoyancy purposes and not for oxygen uptake, and the accumulation of less soluble inert gases in non-ventilated body cavities (Piiper 1965; Pelster 1997), swimbladder tissue of jeju was expected to be exposed to much higher $\mathrm{PO}_{2}$ values than traira swimbladder tissue. Air exposure of the facultative air-breathing fish Heteropneustes fossilis initially resulted in an increase in lipid peroxidation, as indicated by an increase in thiobarbituric acid reactive substances (TBARS), an increase in protein carbonylation and in $\mathrm{H}_{2} \mathrm{O}_{2}$ concentration in muscle tissue, indicating that the higher $\mathrm{PO}_{2}$ values encountered in air indeed result in an elevated ROS production (Paital 2014). Thus, exposure of fish tissues to air may stimulate ROS production, and the results of our present study clearly confirm the hypothesis that swimbladder tissue of the jeju, used as an additional 
air-breathing organ, has an improved antioxidative capacity in comparison to the swimbladder tissue of traira, used as buoyancy organ.

The increased antioxidative capacity extends to the concentration of small antioxidants (GSSG/GSH) as well as to the activity of enzymes involved in ROS degradation. While in the traira the GSSG/GSH concentration was similar in white muscle and in swimbladder tissue, in jeju swimbladder tissue the concentration was almost twice as high as in muscle tissue, and at the species level in the jeju the concentration was significantly higher than in the traira. Glutathione is considered to be a very important component of the antioxidant defense in cells (Storey 1996; Lushchak and Bagnyukova 2006), and an increase in GSH concentration was found in trout hepatocytes after exposure to hyperoxia (Ritola et al. 2002). Similarly, recovery from hypoxia, a situation typically connected to increased ROS production, resulted in a two-fold increase in glutathione concentration in common carp liver (Lushchak et al. 2005b).

Similar to the total glutathione concentration, at the species level the activity of catalase, GR and GPX, enzymes involved in ROS degradation, was higher in the jeju as compared to the traira. Catalase activity was significantly higher in posterior swimbladder of the jeju. An increase in the activity of catalase has been observed during recovery from hyperoxic exposure in goldfish tissues (Lushchak et al. 2005a), supporting the conclusion that the high $\mathrm{PO}_{2}$ values encountered in the swimbladder in the air-breathing jeju may be the cause for the elevated activity of catalase.

Looking at the activity of GR and GPx the difference between the two erythrinid species became even more obvious. Especially GR activity was 3-4 times higher in jeju swimbladder tissue, and in the anterior bladder GPx activity was also significantly elevated. Taken together with the higher GSSG/GSH concentration this suggests that the glutathione-based ROS defense is more important than the immediate ROS degradation by SOD and catalase activity. Similarly, in goldfish the responses of glutathione-dependent enzymes to different levels of oxygen exceed responses of SOD and catalase (Lushchak et al. 2001, 2005a; Bagnyukova et al. 2006). So far most studies focusing on antioxidants in fish have used liver as a tissue highly exposed to reactive oxygen species due to its metabolic activity including, for example, cytochrome P450 activity for the detoxification of xenobiotics (Lushchak et al. 2005a; Bagnyukova et al. 2006). Although the response to oxidative stress induced by changes in oxygen availability in fish tissues does not appear to be uniform (Welker et al. 2013), the consistently elevated GSSG/GSH concentrations and the elevated activities of enzymes involved in ROS defense found in the swimbladder tissue of jeju as compared to traira suggested that using the swimbladder as an air-breathing organ may be connected to special protection against ROS.
According to the vascularization, the posterior swimbladder of the jeju is the part where the oxygen is removed from the gas phase of the bladder. When gulping air the air is initially transferred into the anterior part of the bladder. Gas is then released from the posterior part of the bladder through the operculum, and the posterior bladder is refilled with gas from the anterior part of the bladder (Randall et al. 1981). Accordingly, the anterior part of the bladder is exposed to even higher $\mathrm{PO}_{2}$ values than the posterior part, where the uptake of oxygen results in decreasing $\mathrm{PO}_{2}$ values (Kramer 1978). Nevertheless, except for GR, which showed a significantly higher activity in the posterior part of the jeju swimbladder, no difference in the ROS defense capacity was detected between the two sections.

Somewhat unexpected was the observation that a higher GSH/GSSG concentration was detected in muscle tissue of jeju than in muscle of traira, and GR activity was significantly higher. Based on the assumption that higher tissue $\mathrm{PO}_{2}$ coincides with a higher ROS defense capacity this may indicate that muscle of tissue of jeju obtains better oxygen supply, at least during periods of intensive air-breathing.

In evolutionary terms the relation between the fish swimbladder and the tetrapod lung has frequently been discussed (Perry et al. 2001). Only recently, molecular studies revealed that the swimbladder is homologous to the mammalian lung (Zheng et al. 2011) and there are in fact several common properties in these air-filled organs. Lung function crucially depends on the presence of surfactant produced by type II pneumocytes, and surfactant is also produced by gas gland cells of the fish swimbladder (Prem et al. 2000). A detailed analysis of the surfactant composition of various fish revealed the uniform composition of surfactant from the fish swimbladder and the tetrapod lung (Daniels et al. 2004). Our present results support the hypothesis that jeju, using the swimbladder as an accessory air-breathing organ, has an improved oxidative capacity in the swimbladder tissue when compared to traira swimbladder, used as a buoyancy organ. In a recent study we could also demonstrate that in European eel during silvering, which prepares the animal for the spawning migration to the Sargasso Sea with highly elevated $\mathrm{PO}_{2}$ pressure in the swimbladder at depth, the ROS defense capacity is significantly improved (G. Schneebauer, R. Hanel and B. Pelster, unpublished). It therefore appears likely that the exposure of lung or swimbladder tissue to elevated $\mathrm{PO}_{2}$ values coincides with an enhanced antioxidative capacity of the tissues.

Acknowledgements Open access funding provided by University of Innsbruck and Medical University of Innsbruck. Financial support by INCT ADAPTA-CNPq/FAPEAM, Science without Borders (Brazil), and NSERC Discovery (Canada) is gratefully acknowledged. CMW was supported by the Canada Research Chair Program. ALV is recipient of a research fellowship from Brazilian CNPq. The authors would like to thank Gilda Pelster for support in performing the biochemical assays. 
Open Access This article is distributed under the terms of the Creative Commons Attribution 4.0 International License (http://creativecommons.org/licenses/by/4.0/), which permits unrestricted use, distribution, and reproduction in any medium, provided you give appropriate credit to the original author(s) and the source, provide a link to the Creative Commons license, and indicate if changes were made.

\section{References}

Ali SS, Hsiao M, Zhao HW, Dugan LL, Haddad GG, Zhou D (2012) Hypoxia-adaptation involves mitochondrial metabolic depression and decreased ROS leakage. PLoS One 7:e36801

Bagnyukova TV, Chahrak OI, Lushchak VI (2006) Coordinated response of goldfish antioxidant defenses to environmental stress. Aquatic Toxicol 78:325-331

Bemis WE, Burggren WW, Kemp NE (1987) The biology and evolution of lungfishes. Alan R. Liss Inc, New York, pp 1-383

Bradford MM (1976) A rapid and sensitive method for the quantitation of microgram quantities of protein utilizing the principle of protein-dye binding. Anal Biochem 72:248-254

Chandel NS, Budinger GRS (2007) The cellular basis for diverse responses to oxygen. Free Rad Biol Med 42:165-174

Daniels CB, Orgeig S, Sullivan LC, Ling N, Bennett MB, Schurch S, Val AL, Brauner CJ (2004) The origin and evolution of the surfactant system in fish: insights into the evolution of lungs and swim bladders. Physiol Biochem Zool 77:732-749

Diaz RJ, Breitburg DL (2009) The hypoxic environment. In: Richards JG, Farrell AP, Brauner CJ (eds) Hypoxia. Elsevier, Amsterdam, pp 1-23

Erzurum SC, Danel C, Gillissen A, Chu CS, Trapnell BC, Crystal RG (1993) In vivo antioxidant gene expression in human airway epithelium of normal individuals exposed to $100 \% \mathrm{O}_{2}$. J Appl Physiol 75:1256-1262

Farrell AP, Randall DJ (1978) Air-breathing mechanics in two Amazonian teleosts, Arapaima gigas and Hoplerythrinus unitaeniatus. Can J Zool 56:939-945

Gilmour KM, Perry SF (1994) The effects of hypoxia, hyperoxia or hypercapnia on the acid-base disequilibrium in the arterial blood of rainbow trout. J Exp Biol 192:269-284

Glass ML, Rantin FT (2009) Gas exchange and control of respiration in air-breathing teleost fish. In: Glass ML, Wood SC (eds) Cardio-respiratory control in vertebrates-evolutionary and evolutionary aspects. Springer, Heidelberg, pp 99-120

Gorr TA, Wichmann D, Hu J, Hermes-Lima M, Welker AF, Terwilliger N, Wren JF, Viney M, Morris S, Nilsson GE, Deten A, Soliz J, Gassmann M (2010) Hypoxia tolerance in animals: biology and application. Physiol Biochem Zool 83:733-752

Guppy M (2004) The biochemistry of metabolic depression: a history of perceptions. Comp Biochem Physiol Part B Biochem Molec Biol 139:435-442

Hackett NR, Heguy A, Harvey B-G, O'Connor TP, Luettich K, Flieder DB, Kaplan R, Crystal RG (2003) Variability of antioxidant-related gene expression in the airway epithelium of cigarette smokers. Am J Respir Cell Mol Biol 29:331-343

Halliwell B, Gutteridge JMC (1989) Free radicals in biology and medicine. Clarendon Press, Oxford

Hermes-Lima M (2004) Oxygen in biology and biochemistry: the role of free radicals. In: Storey KB (ed) Functional metabolism: regulation and adaptation. Wiley-Liss, Hoboken, pp 319-368

Hermes-Lima M, Storey JM, Storey KB (1998) Antioxidant defenses and metabolic depression: the hypothesis of preparation for oxidative stress in land snails. Comp Biochem Physiol Part B 120:437-448
Ho JC, Zheng S, Comhair SAA, Farver C, Erzurum SC (2001) Differential expression of manganese superoxide dismutase and catalase in lung cancer. Cancer Res 61:8578-8585

Juca-Chagas R (2004) Air breathing of the neotropical fishes Lepidosiren paradoxa, Hoplerythrinus unitaeniatus and Hoplosternum littorale during aquatic hypoxia. Comp Biochem Physiol Part A Molec Integ Physiol 139:49-53

Kobayashi H, Pelster B, Scheid P (1990) $\mathrm{CO}_{2}$ back-diffusion in the rete aids $\mathrm{O}_{2}$ secretion in the swimbladder of the eel. Respir Physiol 79:231-242

Kramer DL (1978) Ventilation of the respiratory gas bladder in Hoplerythrinus unitaeniatus (Pisces, Characoidei, Erythrinidae). Can J Zool 56:931-938

Kramer DL, McClure M (1982) Aquatic surface respiration, a widespread adaptation to hypoxia in tropical freshwater fishes. Env Biol Fish 7:47-55

Kramer DL, Mehegan JP (1981) Aquatic surface respiration, an adaptive response to hypoxia in the guppy, Poecilia reticulata (Pisces, Poeciliidae). Env Biol Fish 6:299-313

Kramer DL, Lindsey CC, Moodie GEE, Stevens ED (1978) The fishes and the aquatic environment of the central Amazon basin, with particular reference to respiratory patterns. Can J Zool $56: 717-729$

Kristensen T, Rosseland BO, Kiessling A, Djordevic B, Massabau JC (2010) Lack of arterial $\mathrm{PO}_{2}$ downregulation in Atlantic salmon (Salmo salar L.) during long-term normoxia and hyperoxia. Fish Physiol Biochem 36:1087-1095

Li C, Jackson RM (2002) Reactive species mechanisms of cellular hypoxia-reoxygenation injury. Amer J Physiol Cell Physiol 282:C227-C241

Lopes JM, de Lima Boijink C, Florindo LH, Leite CAC, Kalinin AL, Milsom WK, Rantin FT (2010) Hypoxic cardiorespiratory reflexes in the facultative air-breathing fish jeju (Hoplerythrinus unitaeniatus): role of branchial $\mathrm{O}_{2}$ chemoreceptors. J Comp Physiol B 180:797-811

Lushchak VI (2011) Environmentally induced oxidative stress in aquatic animals. Aquatic Toxicol 101:13-30

Lushchak VI (2014) Free radicals, reactive oxygen species, oxidative stress and its classification. Chem -Biol Interact 224:164-175

Lushchak VI, Bagnyukova TV (2006) Effects of different environmental oxygen levels on free radical processes in fish. Comp Biochem Physiol Part B Biochem Molec Biol 144:283-289

Lushchak VI, Bagnyukova TV (2007) Hypoxia induces oxidative stress in tissues of a goby, the rotan Perccottus glenii. Comp Biochem Physiol Part B Biochem Molec Biol 148:390-397

Lushchak VI, Lushchak LP, Mota AA, Hermes-Lima M (2001) Oxidative stress and antioxidant defenses in goldfish Carassius auratus during anoxia and reoxygenation. Amer J Physiol Reg Integ Comp Physiol 280:R100-R107

Lushchak VI, Bagnyukova TV, Husak VV, Luzhna LI, Lushchak OV, Storey KB (2005a) Hyperoxia results in transient oxidative stress and an adaptive response by antioxidant enzymes in goldfish tissues. Int J Biochem Cell Biol 37:1670-1680

Lushchak VI, Bagnyukova TV, Lushchak OV, Storey JM, Storey KB (2005b) Hypoxia and recovery perturb free radical processes and antioxidant potential in common carp (Cyprinus carpio) tissues. Int J Biochem Cell Biol 37:1319-1330

McCord JM, Fridovich I (1969) Superoxide dismutase. An enzymic function for erythrocuprein (hemocuprein)*. J Biol Chem 244:49-55

Morris SM, Albright JT (1981) Superoxide dismutase, catalase, and glutathione peroxidase in the swim bladder of the physoclistous fish, Opsanus tau L. Cell Tiss Res 220:739-752

Morris SM, Albright JT (1984) Catalase, glutathione peroxidase, and superoxide dismutase in the rete mirabile and gas gland epithelium of six species of marine fishes. J Exp Zool 232:29-39 
Muusze B, Marcon J, Van den Thillart G, Almeida-Val V (1998) Hypoxia tolerance of Amazon fish respirometry and energy metabolism of the cichlid Astronotus ocellatus. Comp Biochem Physiol Part A 120:151-156

Oliveira RD, Lopes JM, Sanches JR, Kalinin AL, Glass ML, Rantin FT (2004) Cardiorespiratory responses of the facultative air-breathing fish jeju, Hoplerythrinus unitaeniatus (Teleostei, Erythrinidae), exposed to graded ambient hypoxia. Comp Biochem Physiol Pt A: Molec Integ Physiol 139:479-485

Paital B (2014) Modulation of redox regulatory molecules and electron transport chain activity in muscle of air breathing fish Heteropneustes fossilis under air exposure stress. J Comp Physiol B 184:65-76

Pelster B (1997) Buoyancy at depth. In: Randall DJ, Farrell AP (eds) Deep-Sea Fish. Academic Press, San Diego, pp 195-237

Pelster B (2009) Buoyancy control in aquatic vertebrates. In: Glass ML, Wood SC (eds) Cardio-respiratory control in vertebrates. Springer Verlag, Berlin/Heidelberg, pp 65-98

Pelster B (2011) Swimbladder function and buoyancy control in fishes. In: Farrell AP (ed) Encyclopedia of fish physiology: from genome to environment. Academic Press, San Diego, pp $526-534$

Pelster B (2015) Swimbladder function and the spawning migration of the European eel Anguilla anguilla. Front Physiol 5:486

Perry SF, Wilson RJA, Straus C, Harris MB, Remmers JE (2001) Which came first, the lung or the breath? Comp Biochem. Physiol Part A 129:37-47

Perry SF, Reid SG, Gilmour KM, Boijink CL, Lopes JM, Milsom WK, Rantin FT (2004) A comparison of adrenergic stress responses in three tropical teleosts exposed to acute hypoxia. Amer J Physiol Reg Integ Comp Physiol 287:R188-R197

Piiper J (1965) Physiological equilibria of gas cavities in the body. In: Fenn WO, Rahn H (eds) Handbook of physiology, respiration, American Physiological Society, Bethesda, Maryland, vol 2, pp $1205-1218$

Piiper J, Humphrey HT, Rahn H (1962) Gas composition of pressurized, perfused gas pockets and the fish swim bladder. J Appl Physiol 17:275-282

Prem C, Salvenmoser W, Würtz J, Pelster B (2000) Swimbladder gas gland cells produce surfactant: in vivo and in culture. Am J Physiol Reg Integ Comp Physiol 279:2336-2343

Randall DJ, Farrell AP, Haswell MS (1978) Carbon dioxide excretion in the jeju, Hoplerythrinus unitaeniatus, a facultative air-breathing teleost. Can J Zool 56:970-973

Randall DJ, Burggren WW, Farrell AP, Haswell MS (1981) The evolution of air-breathing in vertebrates. Cambridge University Press, Cambridge, pp 1-133
Rantin FT, Kalinin AL, Glass ML, Fernandes MN (1992) Respiratory responses to hypoxia in relation to mode of life of two erythrinid species (Hoplias malabaricus and Hoplias lacerdae). J Fish Biol 41:805-812

Ritola O, Tossavainen K, Kiuru T, Lindström-Seppä P, Mölsä H (2002) Effects of continuous and episodic hyperoxia on stress and hepatic glutathione levels in one-summer-old rainbow trout (Oncorhynchus mykiss). J Appl Ichthyol 18:159-164

Sies H (2015) Oxidative stress: a concept in redox biology and medicine. Redox Biol 4:180-183

Steen JB (1963) The physiology of the swimbladder in the eel Anguilla vulgaris. III. The mechanism of gas secretion. Acta Physiol Scand 59:221-241

Stevens ED, Holeton GF (1978) The partitioning of oxygen uptake from air and from water by erythrinids. Can J Zool 56:965-969

Storey KB (1996) Oxidative stress: animal adaptations in nature. Braz J Med Biol Res 29:1715-1733

St-Pierre J, Tattersall GJ, Boutilier RG (2000) Metabolic depression and enhanced $\mathrm{O}_{2}$ affinity of mitochondria in hypoxic hypometabolism. Am J Physiol Reg Integ Comp Physiol 279:R1205-R1214

Summarwar S, Verma S (2012) Study of biomarkers of physiological defense against reactive oxygen species during environmental stress. Int J Life Sc Bt Pharm Res 1:198-205

Tripathi RK, Mohindra V, Singh A, Kumar R, Mishra RM, Jena JK (2013) Physiological responses to acute experimental hypoxia in the air-breathing Indian catfish, Clarias batrachus (Linnaeus, 1758). J Biosci 38:373-383

Val AL, Almeida-Val VMF (1995) Fishes of the Amazon and their environment. Springer-Verlag, Berlin, Heidelberg

van Ginneken V, van den Thillart G (2009) Metabolic depression in fish measured by direct calorimetry: a review. Thermochim Acta 483:1-7

Welker AF, Moreira DC, Campos EG, Hermes-Lima M (2013) Role of redox metabolism for adaptation of aquatic animals to drastic changes in oxygen availability. Comp Biochem Physiol Part A Molec Integ Physiol 165:384-404

Wolf K (1963) Physiological salines for freshwater teleosts. Prog Fish-Cult 25:140

Zheng W, Wang Z, Collins JE, Andrews RM, Stemple D, Gong Z (2011) Comparative transcriptome analyses indicate molecular homology of zebrafish swimbladder and mammalian lung. PLoS One 6:e24019 